\title{
Elastofibromatous polyp of the sigmoid colon - A case report and review of gastrointestinal elastofibromas
}

\author{
$Z$ Vesoulis $M D^{1}$, Pars Ravichandran $M D^{1}$, Dimitri Agamanolis $M D^{2}$, Duane Roe $M D^{3}$
}

Z Vesoulis, P Ravichandran, D Agamanolis, D Roe. Elastofibromatous polyp of the sigmoid colon - A case report and review of gastrointestinal elastofibromas. C an J G astroenterol 2003;17(4):275-277.

Elastofibromatous change in the gastrointestinal tract is a rarely reported, usually polypoid lesion of unknown etiology with submucosal stromal change that may mimic amyloid deposition. The constituent amorphous material of the polyp stroma has distinctive features that permit an accurate assessment and diagnosis including: distribution of the material predominantly in the submucosa; distinctive fibrillar and granular appearance of the deposits; thick, irregular, haphazardly arranged bundles of elastic fibres positive for Verhoeff's elastic stain; ultrastructural fibres with an electron dense curvilinear or beaded appearance; lack of amyloid type vascular wall deposits; and lack of amyloid congophilia or crystal violet metachromasia.

The clinical, light microscopic, histochemical and ultrastructural characteristics of this deposited material are reviewed in detail in the present report of a patient who presented with an asymptomatic polypoid lesion of the sigmoid colon. Other reported cases are summarized, and their clinical and pathological features are compared with the current case.

Key Words: Gastrointestinal amyloid; Granulofibrillar deposits; Polypoid elastofibroma

\section{Polype élastofibromateux du sigmoïde - $R$ apport de cas et revue des élastofibromes gastro-intestinaux}

Un changement élastofibromateux dans I'appareil gastro-intestinal est une lésion rarement rapportée, habituellement de type polypoïde d'étiologie inconnue présentant une modification du stroma sous-muqueux et s'apparentant à une accumulation de substance amyloïde. La matière amorphe qui constitue le stroma du polype possède des caractéristiques distinctives qui permettent une évaluation et un diagnostic précis incluant : la distribution de la matière surtout dans la sous-muqueuse; I'apparence granuleuse et fibreuse distinctive des dépôts; les amas épais, irréguliers et désordonnés de fibres élastiques positives à la coloration de Verhoeff; les fibres ultrastructurelles d'apparence curviligne ou perlée dense aux électrons; I'absence de dépôts de type amyloïde dans la paroi vasculaire; et l'absence de congophilie amyloïde ou de métachromasie au cristal violet. Les caractéristiques ultrastructurelles, histochimiques, de microscopie optique et cliniques de ces dépôts sont étudiées en détail dans la présente observation d'un patient présentant une lésion polypoïde asymptomatique du sigmoïde. D'autres cas sont également résumés et leurs caractéristiques pathologiques et cliniques sont comparées à celle du cas à l'étude.

\begin{abstract}
Elastofibromatous lesions are most commonly found as soft tisEsues masses. The prototype elastofibroma dorsi, a relatively uncommon neoplasm-like lesion, usually occurs in the subscapular region of older adults and is thought to be a degenerative phenomenon secondary to repetitive use trauma. Elastofibromas have uncommonly been described in the hand, foot, eye, mediastinum and omentum (1-6). A ccounts of gastrointestinal tract el astofibromatous lesions have been both rare and pathologically variable, reported most often in A sian patients, with lesions of the stomach, sigmoid colon and rectum (7-10). Elastofibromatous lesions have a distinctive histology that includes the presence of broad, fragmented elastic fibres that may be readily identified on hematoxylin and eosin stains $(H \& E)$ but are highlighted with the Verhoeff van Gieson (EVG) and Verhoeff iron hematoxylin staining. Some reports have described a close $H \& E$ morphological similarity of this elastic-rich material to amyloid an important histological distinction with significant clinical implications.
\end{abstract}

\section{CASE REPORT}

A 72-year-old white male patient was referred to the gastroenterology service at Summa Health Systems (A kron, 0 hio) subsequent to the discovery of a rectosigmoid polyp on a routine screening sigmoidoscopy at another institution. $\mathrm{H}$ is past medical history included one episode of transient ischemic attack in the previous year and a cholecystectomy several years before. There was no history of upper or lower gastrointestinal tract bleeding. $\mathrm{H}$ is current medications included Zocar (M erck Frosst, Kirkland, Q uebec), Plavix (B ristol-M yers Squibb/San ofi C anada, M arkham, Ontario), and over the counter vitamin supplements.

U sing standard protocol, a full colonoscopy was performed. The colonoscope was advanced without difficulty to the cecum, and the ileocecal valve was clearly visualized. $0 \mathrm{n}$ withdrawing the instrument, an $8 \mathrm{~mm}$ umbilicated, slightly elongated, smoothly outlined sessile polyp that had a cream to yellow colouration was seen in the sigmoid colon (Figure 1). The gastroenterologist thought this lesion closely resembled a submucosal lipoma. U sing

\footnotetext{
${ }^{1}$ D epartment of Pathology, Summa H ealth System, A kron C ity H ospital; ${ }^{2}$ D epartment of Pathology, A kron C hildren's H ospital; ${ }^{3} \mathrm{D}$ epartment of G astroenterology, Summa H ealth System, A kron C ity H ospital, A kron, O hio, U SA

C orrespondence and reprints: Dr Z Vesoulis, D epartment of Pathology, A kron C ity H ospital, 525 East M arket Street, A kron, 0 hio 44304, USA

Telephone 330-375-3902, fax 330-375-4874, e-mail vesouliz@summa-health. org

Received for publication 0 ctober 31, 2002. A ccepted February 12, 2003
} 


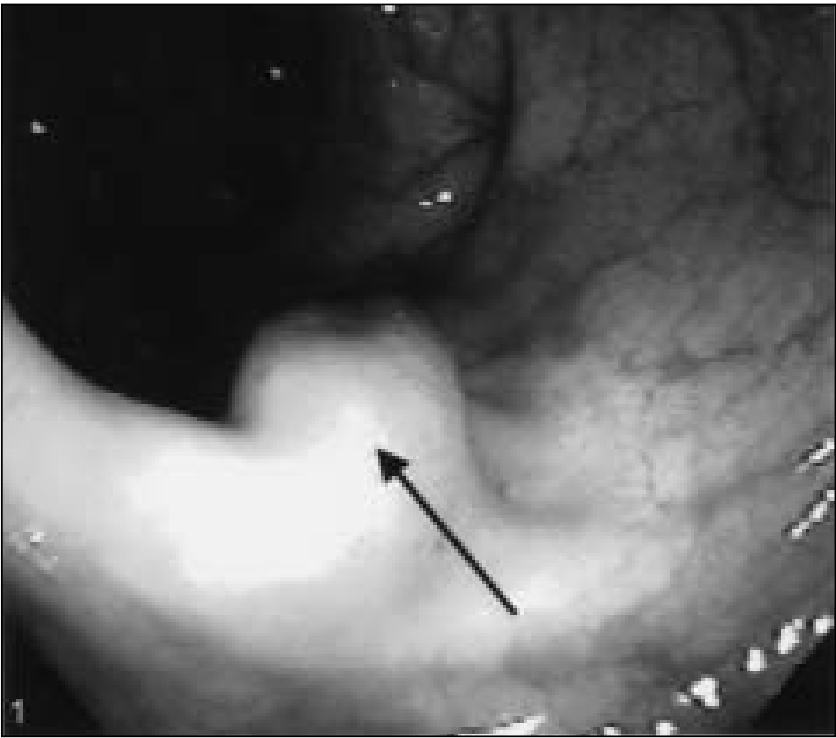

Figure 1) Endoscopic appearance of a sigmoid polypoid elastofibroma showing a $0.8 \mathrm{~cm}$ smooth, slightly elongated sessile polyp, somewhat resembling a gastrointestinal lipoma (arrow)

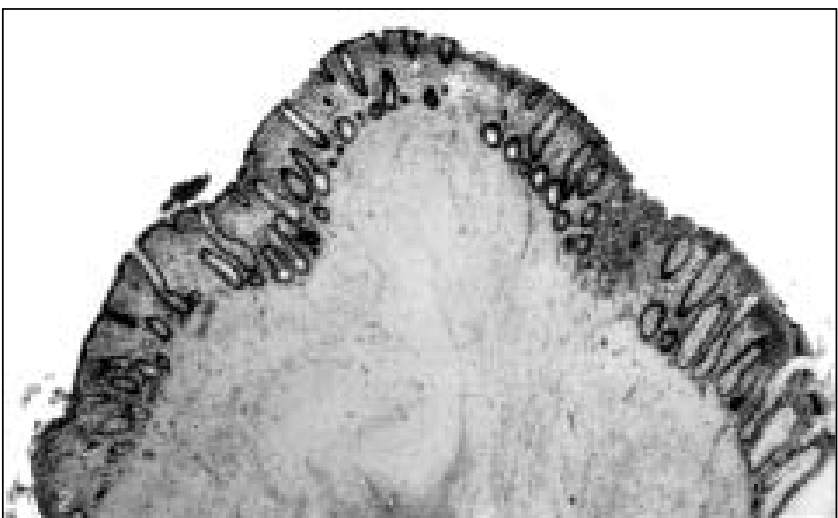

Figure 2) The polypoid sigmoid lesion shows a core of eosinophilic granulofibrillar amorphous material mostly confined to the submucosa and distinct separation from the lamina propria ( $\mathrm{H}$ ematoxylin and eosin stain, original magnification $\times 100$ )

an electrocautery snare, the polyp was completely removed without significant bleeding or other complications. No additional lesions were discovered in the remainder of the colon.

\section{METHODS}

Sigmoid colon biopsy tissue obtained during the colonoscopy was received in 10\% formalin and processed for histology in the usual manner. Sections were stained with $H \& E, E V G, C$ ongo red and crystal violet. For ultrastructural analysis, formalin-fixed tumour tissue was removed from a paraffin block, deparaffinized and transferred to 3\% glutaraldehyde. This material was subsequently fixed in an epoxy resin. Thin plastic sections were stained with uranyl acetate and lead citrate. These sections were evaluated using electron microscopy (Zeiss model 109, 0 berkochen, G ermany).

\section{PAT H OLOGY}

A $0.8 \mathrm{~cm}$ polypoid lesion of the sigmoid colon demonstrated a cut surface with a homogeneous gray-yellow colouration and a soft rubber-like consistency.

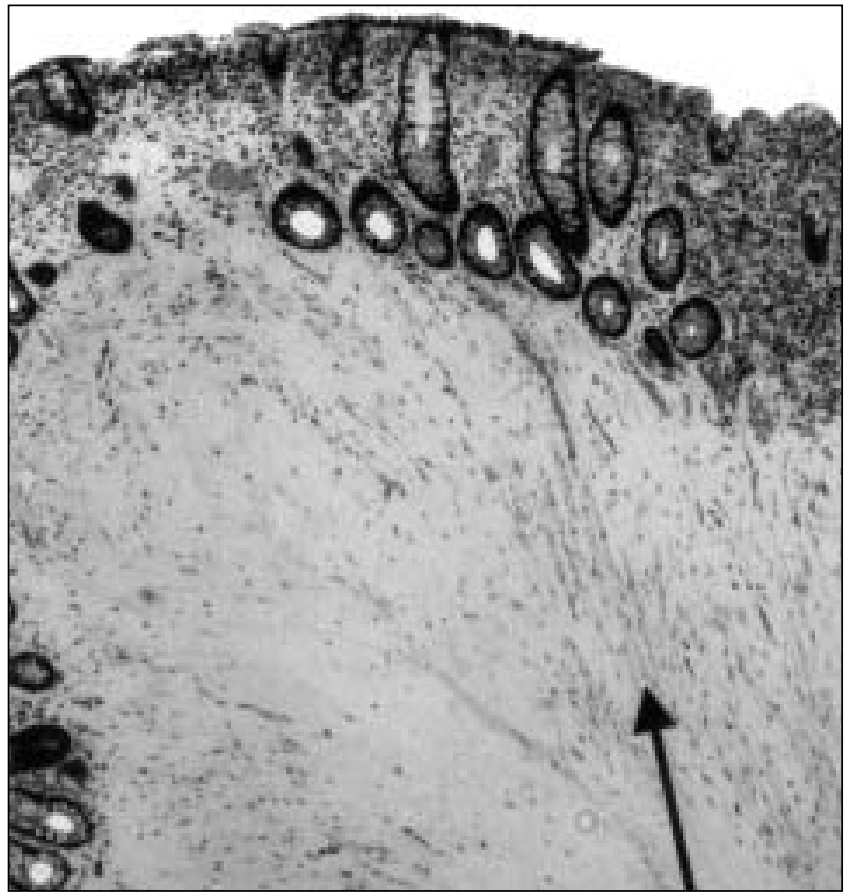

Figure 3) A morphous submucosal material nearly obliterates the muscularis mucosa with splaying of the residual fibres of the muscularis (arrow). (H ematoxylin and eosin stain, original magnification $\times 200$ )

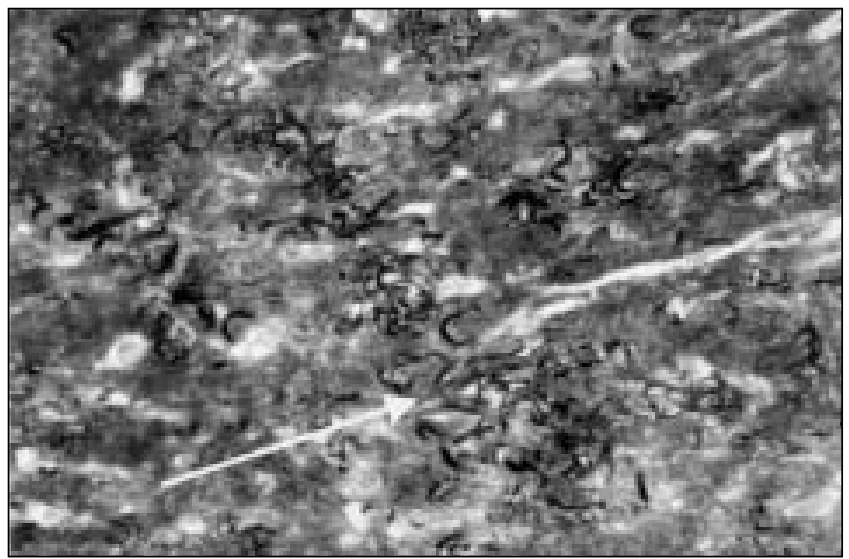

Figure 4) Elastic stain of the submucosal deposits demonstrating numerous randomly distributed, broad and fragmented elastic fibres embedded in a fibrillar and granular matrix. (Verhoeff van $\mathrm{G}$ ieson stain, original magnification $\times 400$ )

$\mathrm{H}$ istologically, the mucosa was unremarkable, but the submucosa was diffusely replaced by a rounded mass of homogeneous granular to fibrillar-appearing eosinophilic material (Figure 2) with splaying of the fibres of the muscularis mucosia (Figure 3). This material did not have the opaque 'fluffy' or 'cracked' appearance of typical amyloid and the distribution of the amorphous material seemed inconsistent with amyloid. There were no significant lamina propria infiltrates or restriction of deposits to submucosal vessels, more typical of gastrointestinal amyloid deposition. Submucosal vessels appeared histologically unremarkable. Special stains for amyloid including C ongo red and crystal violet lacked congophilia, apple-green birefringence or metachromasia. Elastic staining (EVG) was positive for thick, truncated and randomly distributed elastic fibres embedded in the granular matrix (Figure 4). Paraffin-embedded tissue from the polyp was also examined by 
TABLE 1

Reported gastrointestinal elastofibromas

\begin{tabular}{|c|c|c|c|c|c|c|c|c|}
\hline Site (refence) & Polypoid & $\begin{array}{l}\text { Distribution of } \\
\text { elastic fibres }\end{array}$ & Elastic stain & Amyloid stains & Age/Sex & History & $\begin{array}{c}\text { Elastofibroma } \\
\text { dorsi }\end{array}$ & Lesion size \\
\hline Sigmoid (present case) & Yes & Submucosa & EVG + & CR, CV- & $72 / \mathrm{M}$ & Asymptomatic & No & $0.8 \mathrm{~cm}$ \\
\hline Rectum (8) & No & Submucosa & $E V G+$ & CR- & $58 / F$ & Myeloma & No & NR \\
\hline Stomach (7) & No & Submucosa & Elastic + & NR & $69 / F$ & Peptic ulcer & Yes & $6 \times 8 \mathrm{~cm}$ \\
\hline Colon (transverse) (9) & Yes & Submucosa & Elastic + & NR & $49 / \mathrm{M}$ & Colon adenoma & No & $0.5 \mathrm{~cm}$ \\
\hline Sigmoid (10) & Yes & Submucosa & Elastic + & NR & $69 / F$ & Colon adenoma & No & $0.7 \mathrm{~cm}$ \\
\hline
\end{tabular}

CR Congo red; CV Crystal violet; EVG Verhoeff van Gieson; F Female; M Male NR Not reported

electron microscopy. U Itrastructurally, the granulofibrillar material was predominantly composed of collagen fibres, with scattered electron dense, coarse curvilinear and beaded fibres consistent with elastin. Rare oval and spindle shaped nuclei of stromal cells were also seen. There was no ultrastructural evidence of nonbranching fibres typical of amyloid.

\section{DISC U SSION}

When arising in soft tissue, elastofibromas are probably not true neoplasms. These tumour-like growths are slow growing, ill defined masses in older individuals, often with an occupational association involving strenuous manual labour. Typically, these masses are large, reaching $5 \mathrm{~cm}$ to $10 \mathrm{~cm}$ in size and are found in a consistent location between the lower scapula and chest wall. $G$ astrointestinal elastofibromatous change is a lesion of unknown etiology, sometimes attributed to a postinflammatory or posttraumatic condition $(6,7,10)$, somewhat similar to its soft tissue histogenesis. M ost have been reported as small polypoid lesions of the colon. The inciting 'traumatic' incident of their genesis is undefined. A postinflammatory origin seems unlikely, because none of these lesions has ever been associated with any form of specific or idiopathic inflammatory bowel disease. Gastrointestinal elastofibromatous change may be a relatively uncommon and atypical reparative process, because some ultrastructural studies have suggested an overproduction of elastic fibres by fibroblasts and reactive elastin synthesis $(11,12)$.

The current report and at least one previous report indicate the potential differential diagnostic confusion with gastrointestinal amyloid (8). Clinically, the patient with amyloid may have chronic inflammatory or degenerative diseases, a plasma cell dyscrasia, monoclonal gammopathy, or evidence of systemic or multiorgan involvement. Endoscopically, the typical appearance of gastrointestinal amyloid includes granular mucosa, friable hemorrhagic

\section{REFEREN CES}

1. A ustin $P$, Jakobiec FA, I wamoto $T$, H ornblass A. Elastofibroma oculi. A rch O phthalmol 1983;101:1575-9.

2. C ross DL, M ills SE, Kulund DN. Elastofibroma arising in the foot. South Med J 1984;77:1194-6.

3. De N ictolis M , G oteri G, C ampanati G, Prat J. Elastofibrolipoma of the mediastinum. A previously undescribed benign tumor containing abnormal elastic fibers. A m J Surg Pathol 1995;19:364-7.

4. H su JK, C avanagh HD, G reen W R. A n unusual case of elastofibroma oculi. Cornea 1997;16:112-9.

5. Kapff PD, H ocken DB, Simpson RH. Elastofibroma of the hand. J Bone Joint Surg Br 1987;69:468-9.

6. Tsutsumi A, Kawabata K, Taguchi K, Doi K. Elastofibroma of the greater omentum. A cta Pathol Jpn 1985;35:233-41.

7. Enjoji M, Sumiyoshi K, Sueyoshi K. Elastofibromatous lesion of the stomach in a patient with elastofibroma dorsi. A m J Surg Pathol 1985;9:233-7.

8. Goldblum JR, Beals T, W eiss SW. Elastofibromatous change of the rectum. mucosal plaques or thickened folds (13). The typical elastofibroma appears usually as an incidental, innocuous appearing, solitary polypoid lesion in the asymptomatic patient. Histologically, accumulations of amyloid occur most commonly as thick, heterogeneous, opaque, fluffy deposits in the walls of small submucosal vessels. U ncommonly, the amyloid deposits may appear as amorphous, eosinophilic coalescent globules in the lamina propria. In familial M editerranean fever, amyloid deposits may diffusely infiltrate the muscularis propria and the myenteric plexus of the small bowel with consequent hypomotility, bacterial overgrowth and malabsorption (14). Elastofibromatous lesions most commonly occur as polyps of the rectosigmoid region with a distinctive deposition of granulofibrillar material reported exclusively in the submucosa (Table 1). A distinction between elastofibromatous mucosal change and amyloid deposition also can be readily made after examination of slides stained with elastic and amyloid histochemical stains. Elastic stains are uniformly positive for thick dense fibres and the positive staining disappears with elastase digestion in some reported cases in which digestion techniques were used $(9,10)$. Rarely is ultrastructural confirmation or immunohistochemical positive staining with CD34 necessary (15).

$G$ astrointestinal elastofibromas appear to occur on a sporadic basis almost exclusively in the colon with a rare gastric occurrence (7). Patients with these lesions have clinically presented with varied symptoms and findings that appear to be unrelated to their gastrointestinal elastofibroma. O nly few reports have attributed any symptomatology directly to the elastofibroma, with the majority presenting incidentally at endoscopy (Table 1). The primary significance of the gastrointestinal elastofibroma lies in its appropriate recognition as a rare benign polypoid lesion of the colonic mucosa, its distinction from other benign stromal polyps, particularly lipomas or hyperplastic polyps, and its differentiation from gastrointestinal amyloid deposition.
A lesion mimicking amyloidosis. A m J Surg Pathol 1992;16:793-5.

9. H ayashi $\mathrm{K}, \mathrm{O}$ htsuki $\mathrm{Y}$, Sonobe $\mathrm{H}$, et al. Pre-elastofibroma-like colonic polyp: A nother cause of colonic polyp. A cta M ed O kayama 1991;45:49-53.

10. Sakatani T, Shomori K, A dachi H, H osoda A, Ito H. Elastofibroma of the sigmoid colon. Pathol Res Pract 2000;196:205-7.

11. Dixon AY, Lee SH . A n ultrastructural study of elastofibromas. H um Pathol 1980;11:257-62.

12. Kindblom LG, Spicer SS. Elastofibroma. A correlated light and electron microscopic study. Virchows A rch A Pathol A nat H istol 1982;396:127-40.

13. Tada S, Iida M, Yao T, et al. Endoscopic features in amyloidosis of the small intestine: Clinical and morphologic differences between chemical types of amyloid protein. G astrointest Endosc 1994;40:45-50.

14. Ravid M, Sohar E. Intestinal malabsorption: First manifestation of amyloidosis in familial M editerranean fever. G astroenterol 1974:66:446-9.

15. Ruelas Villavicencio A L, A ponte Paredes PS, O rtiz Hidalgo C.

CD-34 expression in elastofibroma. Clinicopathological, histochemical, and immunohistochemical study of four cases. Rev Invest Clin 1999;51:11-6. 


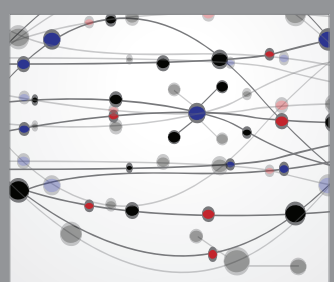

The Scientific World Journal
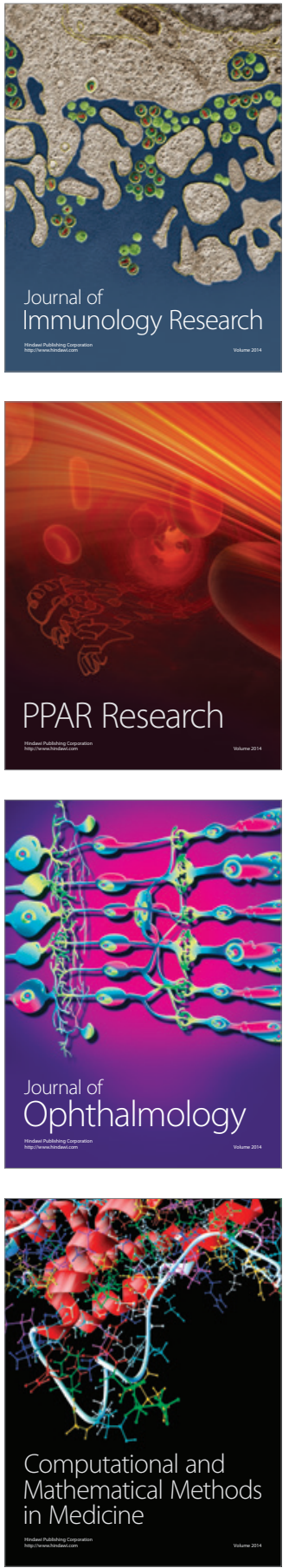

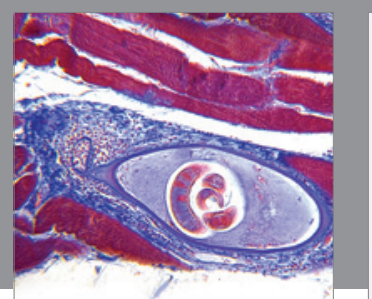

Gastroenterology Research and Practice

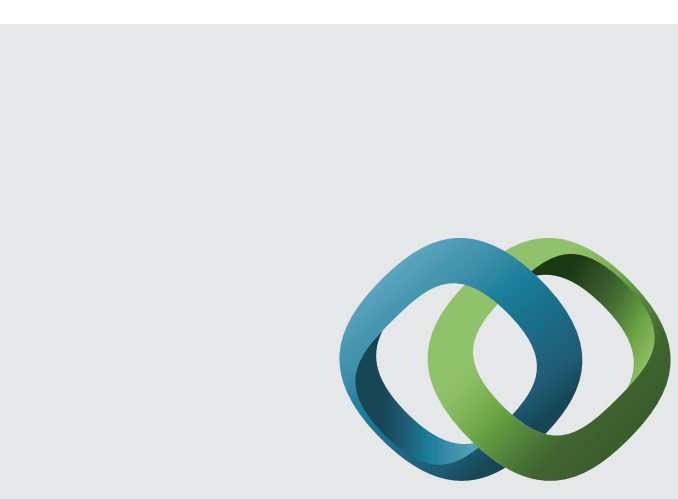

\section{Hindawi}

Submit your manuscripts at

http://www.hindawi.com
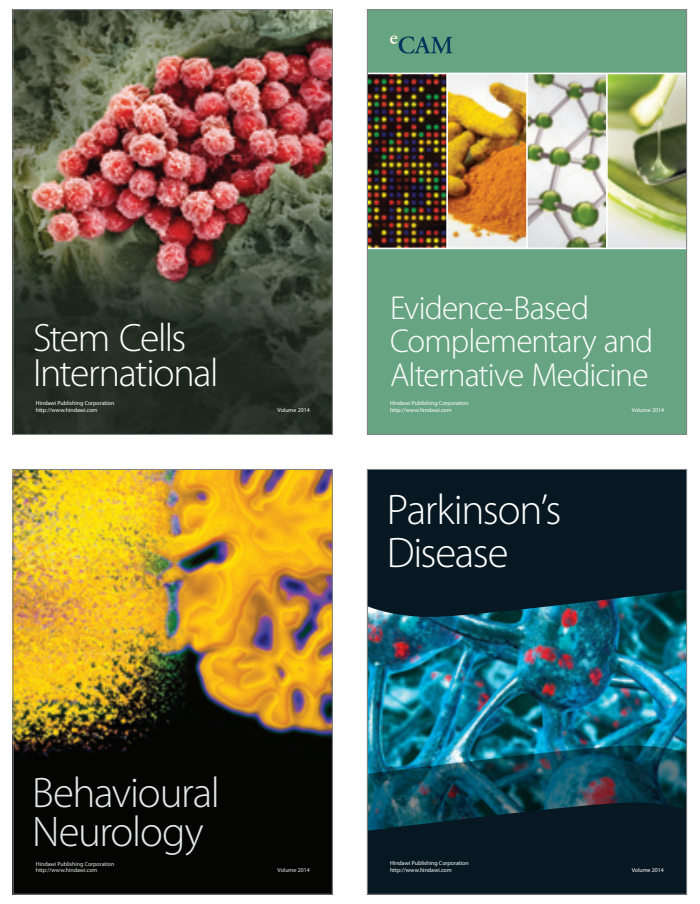
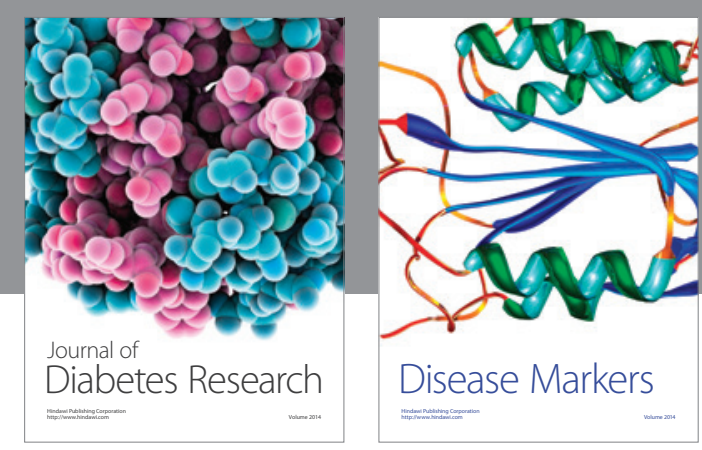

Disease Markers
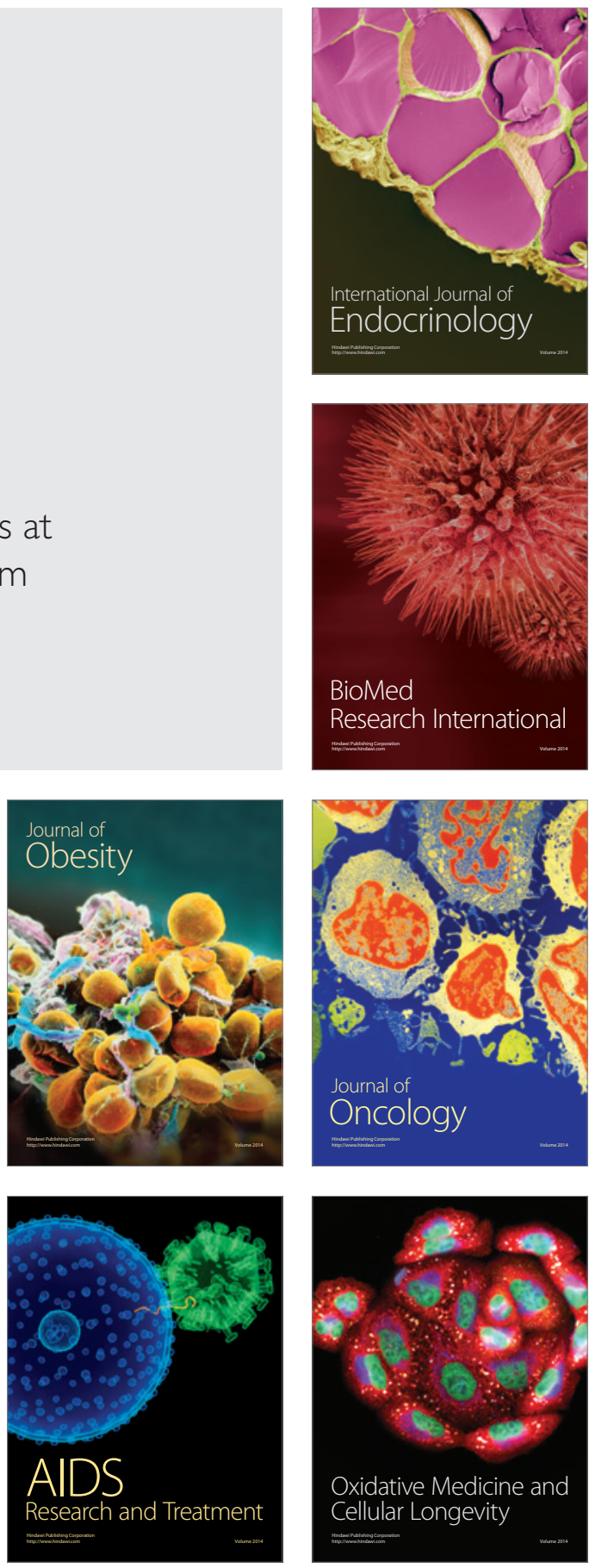